\title{
Desarrollo de la competencia en comunicación lingüística en primer curso de los grados de educación infantil y educación primaria: una experiencia de aula en la UPV/EHU
}

\author{
Asier Romero Andonegi, Universidad del País Vasco, España \\ Iñaki Gaminde, Universidad del País Vasco, España \\ Aintzane Etxebarria, Universidad del País Vasco, España \\ Urtza Garay, Universidad del País Vasco, España
}

\begin{abstract}
Resumen: Con este trabajo pretendemos reflexionar en torno a una experiencia que hemos puesto en marcha este curso en las titulaciones de Educación Infantil y de Educación Primaria de la E.U. de Magisterio de la UPV/EHU. En concreto, nos referimos a la implantación dentro de los nuevos planes EEES de las nuevas titulaciones de Educación Infantil y de Educación Primaria y dentro de la misma en su primer módulo de la asignatura: Desarrollo de la Competencia Comunicativa I. Esta materia cuenta con la particularidad de impartirse en un entorno bilingüe por lo que el desarrollo de las diferentes prácticas (por medio del trabajo grupal cooperativo) ha resultado de sumo interés para la adquisición de una mayor competencia lingüistica.
\end{abstract}

Palabras clave: comunicación oral, competencia comunicativa, bilingüismo

Abstract: In this article we intend to reflect on an experience that we have launched this course in Early Childhood Education degree in Primary Education and the E.U. of Education at the UPV/EHU. Specifically, we refer to the implementation within the new plans of the new degrees (European Higher Education Area) Early Childhood Education and Elementary and Secondary Education within the same in their first module of the course: Communicative Competence Development I. This material has the characteristic of teaching in a bilingual environment so that the development of different practices (through cooperative group work) have been of great interest to acquire greater proficiency.

Keywords: Oral Communication, Communicative Competence, Bilingualism

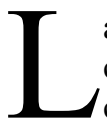

a experiencia que presentamos en esta comunicación se centra en el autoaprendizaje de la competencia comunicativa a través de diferentes ejercicios prácticos (tanto individuales como por medio del trabajo grupal cooperativo) con la particularidad de que estas prácticas se contextualizan en un entorno bilingüe. El objetivo de esta comunicación es el de dar a conocer los resultados de estas experiencias prácticas realizadas en una asignatura centrada en el desarrollo comunicativo y, planteando las siguientes metas:

1. Adquirir una mayor competencia lingüística en lengua vasca y castellano.

2. Brindar orientaciones teóricas para desarrollar la competencia comunicativa en los alumnos, entendida como: el conjunto de procesos de diversos signos lingüísticos, sociolingüísticos, estratégicos y discursivos que el hablante deberá poner en juego para producir o comprender discursos adecuados a la situación, tanto en lo oral como en lo escrito, acorde al contexto de comunicación y al grado de formalización requerido.

3. Desarrollar las capacidades de expresión y comprensión de mensajes producidos en situaciones y contextos diversos, así como la capacidad para reflexionar sobre dichos mensajes y los procedimientos discursivos que lo conforman.

4. Recopilar, analizar, procesar y producir los diferentes textos presentes en el ámbito académico tanto a nivel oral como escrito.

5. Tener contacto directo con el profesorado de una escuela en activo desde el primer curso y entrevistarse con él. 
6. Participar en un trabajo de grupo (proyecto grupal) de forma cooperativa y valerse de la experiencia de un profesional de la enseñanza.

7. Potenciar el autoaprendizaje del alumnado y la reflexión sobre tipos de estilo de comunicación oral y escrita; y por otra parte, reflexionar sobre la conveniencia de la utilización del registro estándar u otro con objeto de favorecer el acercamiento entre los diferentes estamentos que conviven en los centros escolares.

El Aprendizaje Cooperativo, como estrategia metodológica en el aula, permite la construcción del conocimiento en base a la interacción social del alumno con sus demás compañeros, los contenidos o materiales de aprendizaje y el docente. El realizar grupos de trabajo para la construcción del aprendizaje, promueve el desarrollo de liderazgos múltiples al manifestarse los distintos talentos e inteligencias de los alumnos, permitiendo un verdadero trabajo en equipo y un aprendizaje más significativo. Además, si este tipo de aprendizaje dinámico y cooperativo se enmarca en el contexto y desarrollo de la competencia en comunicación lingüística se posibilita y se contribuye a mejorar la competencia comunicativa pues se trabajan las normas básicas de comunicación (Chomsky, 1965; Canale, 1989; Hirst y Slavik, 1990).

\section{Descripción del trabajo}

Entre los principios clave que podemos destacar en la configuración de los nuevos títulos de Educación Infantil y de Educación Primaria en nuestra universidad, están la interdisciplinariedad y la coherencia en la secuencia de la propuesta formativa. Como garante de estos principios, hemos optado por una estructura modular, de manera que el plan de estudios consta de cinco módulos, distribuidos por cuatrimestres durante los tres primeros años, y un último curso, el cuarto, centrado en la elección/realización de cinco especialidades diferentes.

Cada módulo está asociado a unas competencias generales y específicas y adopta una perspectiva interdisciplinar que hace confluir las distintas disciplinas en la realización de una tarea, denominada Actividad Interdisciplinar de Módulo (AIM), que requiere articular saberes teóricos y procedimentales relativos a las distintas materias que configuran el módulo. Esta articulación interna de los módulos exige una relación estrecha entre las disciplinas que los conforman al objeto de mantener coherencia y ofrecer una visión de globalidad, que supere la visión atomizada de los contenidos disciplinares, en consonancia con la cultura profesional que pretendemos. Este Módulo 1 se desarrollo el primer semestre del primer curso de la titulación. Las materias que lo componen son las siguientes: Sociología de la Educación, Teoría e Historia de la Educación, Función Docente, Desarrollo de la Competencia Comunicativa I y Psicología del Desarrollo en la Edad Escolar.

Esta asignatura Desarrollo de la Competencia Comunicativa I se encuadra dentro del primer Módulo de las nuevas titulaciones de Educación Infantil y de Educación Primaria y se centra, principalmente, en primer lugar en la adquisición y comprensión de los conceptos básicos para el análisis y la producción de discursos y textos; y en segundo lugar, en la comprensión y producción de textos orales y escritos, atendiendo específicamente a los géneros discursivos más comunes en el ámbito académico. Así mismo, esta materia se complementa con la asignatura del tercer módulo Desarrollo de la Competencia Comunicativa II. Por su parte, esta segunda materia centra su objetivo principalmente en la observación y análisis de textos orales y escritos del ámbito escolar en torno a los elementos textuales y contextuales que los configuran; y en el análisis y producción de textos en el ámbito profesional. (ver Tabla 1). 
Tabla 1. Datos generales de la asignatura

\begin{tabular}{|c|l|l|}
\hline $\begin{array}{c}\text { Centro y univer- } \\
\text { sidad }\end{array}$ & $\begin{array}{l}\text { Educación Infantil } \\
\text { Escuela Universitaria de Magisterio de Bil- } \\
\text { bao de la Universidad del País Vasco }\end{array}$ & $\begin{array}{l}\text { Escuela Universión Primaria de Magisterio } \\
\text { de Bilbao de la Universidad del País } \\
\text { Vasco }\end{array}$ \\
\hline $\begin{array}{c}\text { Departamento } \\
\text { Titulación }\end{array}$ & Departamento de Didáctica de la Lengua & $\begin{array}{l}\text { Departamento de Didáctica de la } \\
\text { Lengua }\end{array}$ \\
\hline Asignatura & $\begin{array}{l}\text { Desarrollo de la Competencia Comunicativa } \\
\text { I }\end{array}$ & $\begin{array}{l}\text { Desarrollo de la Competencia Comu- } \\
\text { nicativa I }\end{array}$ \\
\hline $\begin{array}{c}\text { Curso y cuatri- } \\
\text { mestre }\end{array}$ & Primero; primer cuatrimestre & Primero; primer cuatrimestre \\
\hline $\begin{array}{c}N^{o} \text { de créditos } \\
\text { 6 ECTS (36 horas para clases magistrales y }\end{array}$ & $\begin{array}{l}\text { 6 ECTS (24 horas para clases magis- } \\
\text { trales, 31 horas para prácticas de aula } \\
\text { y 5 horas para seminarios) }\end{array}$ \\
\hline $\begin{array}{c}\text { Distribución de } \\
\text { la docencia }\end{array}$ & $\begin{array}{l}\text { Clase en tres sesiones semanales, dos de } \\
\text { clases prácticas y una de magistral. }\end{array}$ & $\begin{array}{l}\text { Clase en tres sesiones semanales, dos } \\
\text { de clases prácticas y una de magistral. }\end{array}$ \\
\hline $\begin{array}{c}N^{o} \text { de alumnos } \\
\text { 120 alumn@s (dividid@s en dos grupos para } \\
\text { teoría y en cuatro grupos para las prácticas) }\end{array}$ & $\begin{array}{l}\text { 240 alumn@s (dividid@s en dos } \\
\text { grupos para teoría, en cuatro grupos } \\
\text { para las prácticas de aula y seis gru- } \\
\text { pos para seminarios ) }\end{array}$ \\
\hline
\end{tabular}

En cuanto al horario de clases, se distribuye durante la semana en horario de mañana de lunes a viernes, computando semanalmente cada grupo un total de dos horas y media de clase magistral más una hora y media de clase práctica en el caso de Educación Infantil; y de un total de dos horas y media de clase magistral, más una hora y media de clase práctica y una hora para seminario en el caso de Educación Primaria. Estas clases magistrales son eminentemente prácticas siguiendo el siguiente formato: introducción teórica, breve exposición profesor-alumno, interrogantes iniciales y debate en grupo, desarrollo de la práctica didáctica (acción-reflexión) y finalmente evaluaciónreflexión sobre la sesión.

De forma no presencial, se llevan a cabo tutorías virtuales, foros de información general, de discusión sobre las unidades temáticas, de evaluación de la asignatura y del profesor, lecturas en el aula virtual y entrega de trabajos. En este contexto, hay que señalar, que hemos establecido como requisito imprescindible el seguimiento de la asignatura por medio de la plataforma virtual Moodle (Imagen 1).

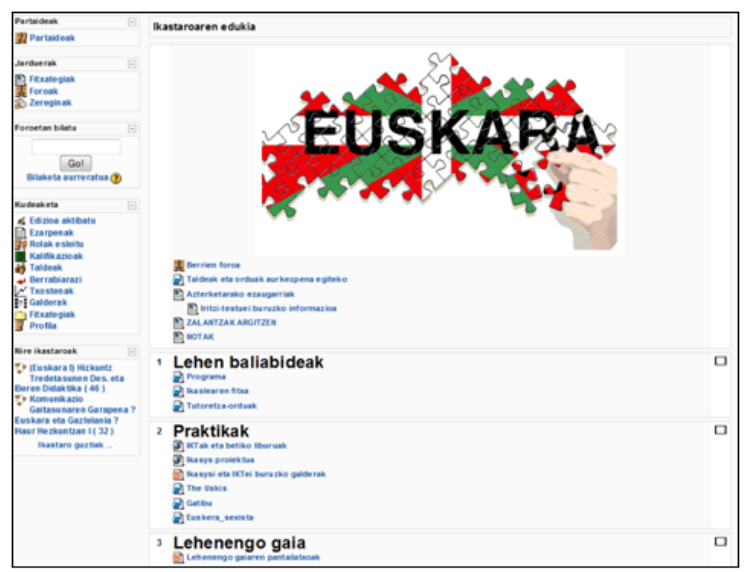

Imagen 1: Aula virtual de Moodle 
Como ya hemos señalado anteriormente, esta asignatura se encuadra dentro del Módulo 1, desarrollando las siguientes competencias que aparecen reflejadas en la Tabla 2.

Tabla 2. Competencias específicas de la asignatura Desarrollo de la Competencia Comunicativa I

Competencias Especificas Conceptuales (Conocimiento Teórico):

1. Analizar, procesar y producir diferentes textos presentes en el ámbito académico.

2. Participar en actividades colectivas, por medio del trabajo cooperativo e individual.

3. Adquirir una mayor competencia lingüística en la lengua vasca.

Competencias Específicas Procedimentales (Conocimiento Práctico):

1. Habilidad para trabajar de forma autónoma, construyendo su propio aprendizaje.

2. Habilidad para trabajar en grupo, asumiendo la responsabilidad y el compromiso que de ello se deriva. Competencias Especificas Actitudinales

1. Capacidad de comunicación interpersonal

2. Compromiso con el trabajo colaborativo

3. Actitud reflexiva, crítica e indagadora en relación con el propio proceso de aprendizaje, así como positiva hacia el trabajo cooperativo, asumiendo su importancia en la práctica docente, para la mejora y el desarrollo profesional.

Esta experiencia que se presenta se ha llevado a cabo durante el curso 2011-2012 y, tal y como se observa en la Tabla 3, las actividades presenciales de enseñanza-aprendizaje que hemos utilizado para el desarrollo del plan docente están relacionadas con el desarrollo de la competencia comunicativa en los alumnos. En este contexto y, para lograr este fin, por una parte, se han realizado una serie de diferentes prácticas presenciales de carácter individual, centradas en la comprensión y expresión oral y escrita basados en textos de diferente tipología. Estas prácticas ayudan a interiorizar algunos de los aspectos referidos a la aplicación práctica de los contenidos conceptuales de los temas desarrollados (Tabla 4).

Tabla 3: Actividades de práctica

\begin{tabular}{|l|l|}
\hline $\begin{array}{c}\text { Actividades } \\
\text { Enseñanza- } \\
\text { Aprendizaje }\end{array}$ & \multicolumn{1}{c|}{ Descripción } \\
\hline Práctica individual_1 & $\begin{array}{l}\text { Relato histórico-personal de la adquisición de las dos lenguas oficiales de la CAV } \\
\text { y su grado de utilización atendiendo a los contextos sociolingüísticos en los que se } \\
\text { desenvuelve el alumnado (entorno familiar, escolar y social) }\end{array}$ \\
\hline Práctica individual_2 & $\begin{array}{l}\text { Comparación de la realidad lingüística escolar de nuestros alumnos/as con la } \\
\text { vivida por sus padres y abuelos tanto en lo referente a la lengua oficial presente en } \\
\text { el aula como a los idiomas extranjeros. }\end{array}$ \\
\hline Práctica individual_3 & $\begin{array}{l}\text { Observación y análisis de los idiomas que habitualmente se utilizan en el entorno } \\
\text { escolar y descripción de los idiomas extranjeros presentes en el Proyecto Lingǘstico } \\
\text { del Centro (PLC), atendiendo principalmente a la comprensión y expresión oral y } \\
\text { escrita. }\end{array}$ \\
\hline Práctica individual_4 & $\begin{array}{l}\text { Análisis comparativo entre diferentes canciones: una canción popular infantil } \\
\text { tradicional, una canción popular infantil moderna y algunos textos actuales de } \\
\text { bertsolaris jóvenes. }\end{array}$ \\
\hline Práctica individual_5 & $\begin{array}{l}\text { Trabajar las técnicas de estructuración del cuento infantil a través de cuentos } \\
\text { tradicionales y modernos. }\end{array}$ \\
\hline Práctica grupal_1 & $\begin{array}{l}\text { Análisis documental de anuncios publicitarios utilizados en medios audiovisuales } \\
\text { y medios escritos actuales. }\end{array}$ \\
\hline Práctica grupal_2 & $\begin{array}{l}\text { Análisis de la actual situación del euskara a través de la lectura de diferentes ar- } \\
\text { tículos de opinión (columna, editorial y ensayo). }\end{array}$ \\
\hline Práctica grupal_3 & $\begin{array}{l}\text { Visualización de varios videos (Jean Paul Bronckart y Charles Jang) relacionados } \\
\text { con el Lenguaje (adquisición, desarrollo psicológico e historia) y análisis de la } \\
\text { introducción realizada a dichas conferencias por profesoras de la UPV para analizar } \\
\text { la utilización alterna de las lenguas oficiales de nuestra comunidad. }\end{array}$ \\
\hline Práctica grupal_4 & Grabarse contando un cuento interactivo/narración y visualizarlo posteriormente \\
\hline
\end{tabular}




\begin{tabular}{|l|l|}
\hline & utilizando la técnica de la autoconfrontación. \\
\hline Práctica grupal_5 & $\begin{array}{l}\text { Análisis del discurso del rector de la UPV en la apertura oficial del inicio de curso } \\
\text { académico y análisis de la utilización del euskara, castellano e inglés que hizo en } \\
\text { dicho discurso. }\end{array}$ \\
\hline
\end{tabular}

Tabla 4: Objetivos de las prácticas

\begin{tabular}{|c|c|}
\hline Prácticas & Objetivos \\
\hline $\begin{array}{l}\text { Prácticas individuales } \\
1,2 \text { y } 3\end{array}$ & $\begin{array}{l}\text {-Ser consciente de la realidad socio-lingüística actual de la CAPV y la evolución que } \\
\text { ha experimentado en las últimas décadas. } \\
\text {-Ser capaz de analizar la actual realidad socio-lingüística escolar. } \\
\text {-Percatarse del grado de implantación escolar del Modelo de Enseñanza Trilingüe } \\
\text { propuesto por el Departamento de Educación del Gobierno Vasco y otros modelos } \\
\text { lingüísticos planteados en otros centros escolares (Eleanitz-English proeiktua de la } \\
\text { Federación de Ikastolas). } \\
\text {-Observar el fenómeno de la inmigración y sus consecuencias en el plano lingüístico. }\end{array}$ \\
\hline Práctica individual 4 & $\begin{array}{l}\text {-Ser consciente de las diferencias entre el lenguaje escrito y oral; y dentro de este } \\
\text { último de las variedades dialectales que presenta la lengua vasca. } \\
\text {-Percatarse de la necesidad de transmitir el lenguaje coloquial familiar y las dife- } \\
\text { rencias entre éste y el lenguaje formal que se utiliza en el contexto escolar. } \\
\text {-Trabajar el desarrollo y adquisición del lenguaje a través de textos orales y escritos } \\
\text { de la tradición popular. } \\
\text {-Descubrir diferentes formas de comunicación y representación, utilizando sus } \\
\text { técnicas y recursos más básicos, y disfrutar con ellas. }\end{array}$ \\
\hline Práctica individual 5 & $\begin{array}{l}\text {-Favorecer la expresión oral y comprensión lectora a través de la producción y } \\
\text { comprensión de cuentos infantiles. }\end{array}$ \\
\hline Práctica grupal_1 & $\begin{array}{l}\text {-Ser consciente de la importancia del destinatario del mensaje. } \\
\text {-Observar los diferentes tipos de comunicación oral y escrita y valor funcional de } \\
\text { su mensaje. }\end{array}$ \\
\hline Práctica grupal_2 & $\begin{array}{l}\text {-Percatarse de la actual realidad sociolingüística en el uso del euskara en los dife- } \\
\text { rentes ámbitos de la sociedad. } \\
\text {-Trabajar el texto argumentativo y sus procedimientos organizativos, argumentati- } \\
\text { vos y lingüísticos. } \\
\text {-Trabajar las técnicas del resumen y de la exposición oral } \\
\text {-Analizar las microhabilidades de la expresión escrita. }\end{array}$ \\
\hline Prácticagrupal_3 & $\begin{array}{l}\text {-Trabajar el texto expositivo académico a través de la conferencia. } \\
\text {-Trabajar las técnicas de la exposición oral. } \\
\text {-Analizar las microhabilidades de la expresión oral. } \\
\text {-Observar la utilización del multilingüismo. }\end{array}$ \\
\hline Práctica grupal_4 y 5 & $\begin{array}{l}\text {-Favorecer el desarrollo del lenguaje (expresión oral) a través del cuento en las } \\
\text { distintas etapas de adquisición del lenguaje en 1@s niñ@s. } \\
\text {-Conocer las formas tradicionales de inicio y finalización de los cuentos atendiendo } \\
\text { a nuestra tradición oral. } \\
\text {-Fomentar la participación activa de todos los miembros del grupo. } \\
\text {-Analizar el texto expositivo académico por medio de las lenguas oficiales de la } \\
\text { CAV y del inglés y la utilización alterna de varias lenguas sin la repetición de la } \\
\text { información. }\end{array}$ \\
\hline
\end{tabular}

Por otra parte, el alumnado ha elaborado un proyecto de grupo (PG) que ha consistido en la realización de un informe sobre la producción escrita en un centro escolar de la CAPV seleccionado por ellos, pero atendiendo a los diferentes tipos de centros escolares que existen en nuestra comunidad: centros públicos y centros concertados. Una vez elegido el centro escolar, cada grupo (formado por $5 / 6$ alumnos y alumnas) ha tenido que realizar una entrevista a un miembro de la dirección del centro que, a su vez, tenía que ser un o una profesional experimentado/a en Educación Infantil y/o Educación Primaria, y recabar información sobre el tipo de comunicación escrita que se producía en dicho centro escolar. A continuación, han tenido sesiones de seguimiento con el profesorado de la asignatura, en las que se les ha explicitado el planteamiento del trabajo a 
realizar, las herramientas y documentos a consultar e, igualmente, se les ha orientado en la realización del informe escrito y en la preparación de la exposición oral del trabajo ante toda la clase.

Entre los objetivos que se buscan con la realización de este proyecto podemos destacar los siguientes:

- Analizar la producción escrita que se utiliza en un centro escolar, atendiendo a los diferentes destinatarios: profesorado, alumnado, padre-madre/tutores e instituciones u otro tipo de entidades.

- Observar el Proyecto Lingüístico del Centro y su implementación en la realidad escolar a través de su producción escrita. En este contexto, analizar los problemas derivados de una mala praxis: errores en la redacción del documento, ausencia de formularios, etc.

- Desarrollar tanto las capacidades de expresión y comprensión de los mensajes producidos en esta específica tipología documental, así como la capacidad para reflexionar sobre los mensajes escritos y los procedimientos discursivos que lo conforman.

- Analizar la utilización de las dos lenguas oficiales en los textos escritos.

\section{Sistema de evaluación}

En este apartado vamos a presentar el sistema de evaluación seguido en esta asignatura Desarrollo de la Competencia Comunicativa I. Así, se describe el sistema de evaluación al que puede optar el alumnado que cursa dicha asignatura, manteniendo siempre un proceso de diálogo y negociación previa de las mismas, siendo la ética y el compromiso formal, los valores fundamentales que guían este proceso. Por otra parte, aunque sea una asignatura presencial, exige también una importante implicación con el uso de las TIC y, por tanto, el sistema de evaluación (instrumentos) va a estar condicionado a ello (ver imagen 2). Además, es necesario destacar, que la obligatoriedad presencial es necesaria para la adquisición de experiencias relacionadas con la competencia lingüística: comprensión/expresión oral y escrita (Iriondo, 2009).

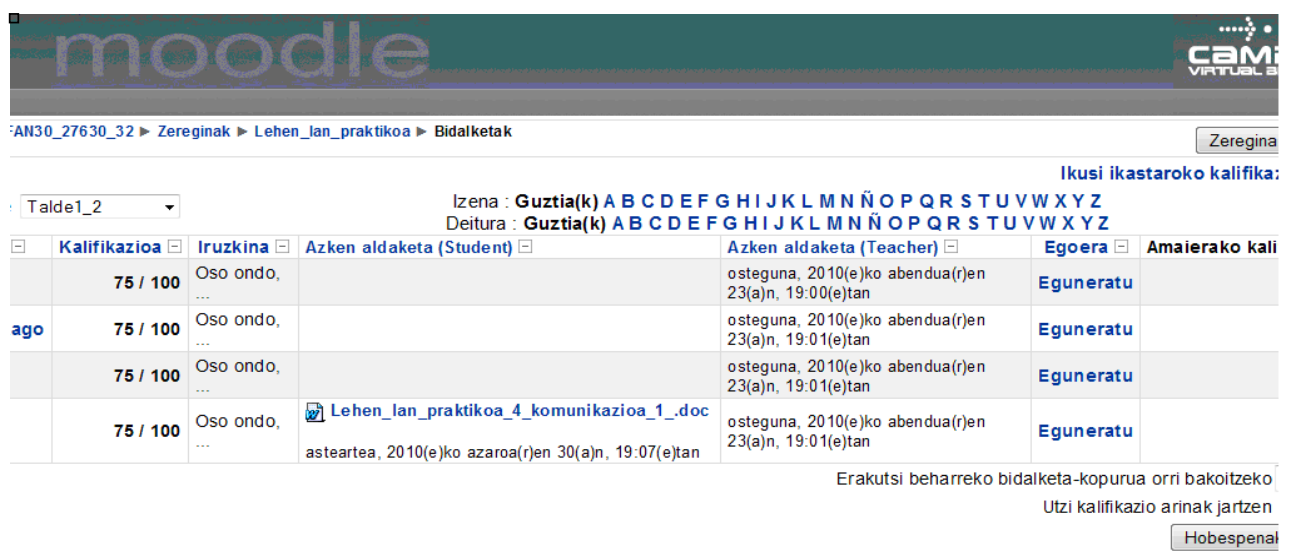

Imagen 2: Evaluación de los trabajos a través de Moodle

Desde un principio, se ha ofertado al estudiante dos opciones para trabajar en la asignatura (Tabla 5), aunque hay que señalar que en los nuevos grados de Educación Infantil y de Educación Primaria la asistencia a clase es necesaria, al menos en un $80 \%$ (Opción A). Además, se han tenido en cuenta una serie de aspectos y/o criterios, entre los que podemos destacar: asistencia a las sesiones presenciales, reflexión sobre los contenidos teórico-prácticos, reflexión crítica y emisión de juicios de valor sobre las lecturas, participación en los foros-debates presenciales o virtuales con exposición de ideas, participación en las puestas en común de análisis y evaluación de las sesiones, participación activa con interés en las actividades prácticas, comprensión del 
enfoque práctico de los temas, capacidad de diseñar actividades según los objetivos propuestos, capacidad de desarrollar correctamente los trabajos propuestos, cooperación grupal e interés por los contenidos teórico-prácticos de la asignatura.

Tabla 5. Características de las dos opciones de evaluación

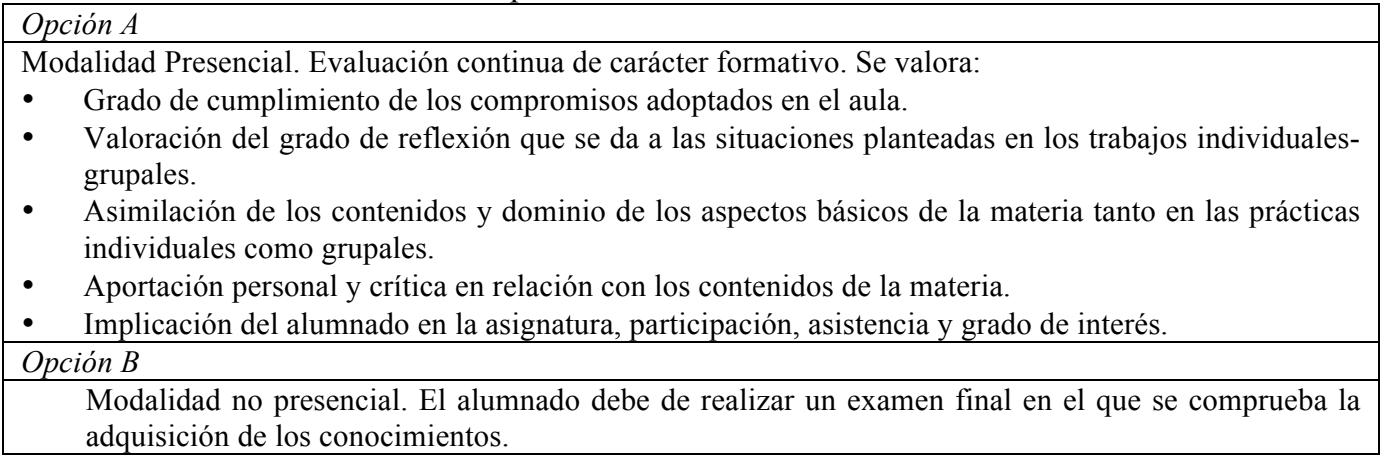

Atendiendo a la modalidad presencial, que es la exigida en los nuevos grados de Educación Infantil y de Educación Primaria, hay dos consideraciones que nos gustaría señalar. En primer lugar la importancia que adquiere la lectura y comentario de artículos en la realización de los trabajos individuales y en grupo, ya que se trata de desarrollar las siguientes competencias generales: búsqueda de documentación, análisis y valoración crítica de la información recibida y utilización correcta de las referencias bibliográficas en los trabajos académicos. En segundo lugar, en la presentación oral de las prácticas y del proyecto de grupo (PG) que se realiza ante toda la clase. En este contexto, no hay que olvidar que entre los objetivos de la asignatura la aplicación práctica de los recursos de la expresión oral es fundamental (ver tabla 6).

Tabla 6: Sistema de calificación y puntuación

\begin{tabular}{|l|l|c|}
\hline $\begin{array}{l}\text { Realización de los traba- } \\
\text { jos individuales y en } \\
\text { grupo }\end{array}$ & $\begin{array}{l}\text { A lo largo de las diferentes unidades temáticas se propon- } \\
\text { drán diferentes trabajos. Cada unidad temática contiene un } \\
\text { trabajo individual y uno grupal que el alumnado debe } \\
\text { desarrollar de forma tutorizada (presentación de diseño, } \\
\text { seguimiento y entrega), debiéndose entregar en clase o } \\
\text { enviarlo en formato electrónico en la fecha pactada. }\end{array}$ & $15 \%$ \\
\hline $\begin{array}{l}\text { Realización de un proyec- } \\
\text { to de análisis de textos } \\
\text { escritos en un centro } \\
\text { escolar de la CAPV (Pro- } \\
\text { yecto de grupo) }\end{array}$ & $\begin{array}{l}\text { Se trata de buscar la aplicación práctica de lo aprendido } \\
\text { anteriormente utilizando los recursos vistos hasta el mo- } \\
\text { mento. Entrevista a un miembro de la dirección de un } \\
\text { centro escolar de Infantil y transcripción de ésta. Recopi- } \\
\text { lación y análisis de los textos escritos utilizados en dicho } \\
\text { centro escolar }\end{array}$ & $35 \%$ \\
\hline $\begin{array}{l}\text { Examen en convocatoria } \\
\text { oficial }\end{array}$ & $\begin{array}{l}\text { Se realiza un examen final (en grupo) de las diferentes } \\
\text { unidades temáticas desarrolladas durante el curso. }\end{array}$ & $34 \%$ \\
\hline $\begin{array}{l}\text { Trabajo interdisciplinar } \\
\text { AIM) }\end{array}$ & $\begin{array}{l}\text { Cada módulo del Grado está asociado a unas competencias } \\
\text { generales y específicas y adopta una perspectiva interdis- } \\
\text { ciplinar que hace confluir las distintas disciplinas en la } \\
\text { realización de una tarea, denominada Actividad Interdisci- } \\
\text { plinar de Módulo (AIM), que requiere articular saberes } \\
\text { teóricos y procedimentales relativos a las distintas mate- } \\
\text { rias que configuran el módulo. }\end{array}$ & $16 \%$ \\
\hline
\end{tabular}

Hasta aquí se han presentado los instrumentos propios de la evaluación de esta asignatura que nos permite controlar los aprendizajes. La evaluación tiene además una parte fundamental orientada a la evaluación del proceso organizada en base a los siguientes recursos: evaluación institucional, evaluación del profesorado y evaluación de la asignatura por medio de un informe de autoevaluación realizado por los alumnos y alumnas (opcional). 
1. La evaluación institucional es la realizada por la propia Universidad de cada una de las asignaturas que se imparten en todas las titulaciones. Supone un primer referente centrado en el docente y en la asignatura que imparte, realizado mediante una encuesta de evaluación de la asignatura que se realiza al concluir el módulo. Los resultados de dicha evaluación no se conocerán hasta septiembre de este año 2012.

2. La evaluación de la asignatura por parte del alumnado se ha recogido a través de un cuestionario habilitado en la plataforma Moodle con el objeto de conocer la opinión del alumnado sobre las actividades que han realizado en la asignatura: aspectos positivos, aspectos a mejorar y valoración de lo aprendido. La valoración del sistema de evaluación llevado a cabo ha sido muy positiva y han considerando que es coherente con el proceso de aprendizaje y ayuda al desarrollo de las competencias profesionales marcadas al comienzo de la asignatura. Así mismo, han valorado muy positivamente la clara explicación de los criterios de evaluación con anterioridad a la realización de las actividades prácticas y del proyecto grupal en el centro escolar. Asimismo, se han valorado positivamente las actividades prácticas realizadas y el proyecto de grupo (PG), ya que les ha permitido conocer, observar y analizar desde un centro educativo real los contenidos temáticos de la asignatura (ver Imagen 3). Se valora muy positivamente el proyecto de grupo (PG), ya que ha permitido contextualizar el concepto de producción escrita en un centro educativo concreto seleccionado por cada grupo de alumnos y alumnas.

Se valora, también, que se ha dedicado poco tiempo a observar y analizar algunos modelos educativos (CLIL o Tratamiento Integrado de Lenguas) de sumo interés y que condicionarán de una forma sustancial los actuales modelos fijados en los Proyectos Lingüísticos de Centro.

Por otra parte, el aprendizaje autónomo ha sido valorado muy positivamente, ya que en la autoevaluación realizada, los alumnos y alumnas han considerado muy acertadas las prácticas para el desarrollo de esta competencia.

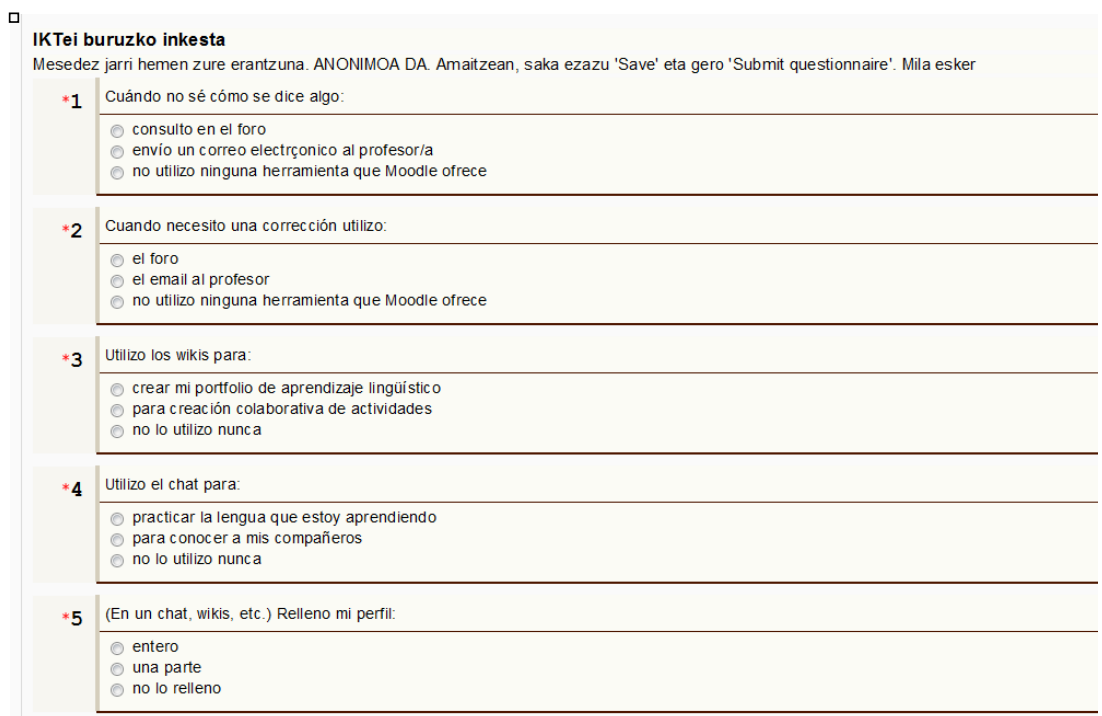

Imagen 3: Evaluación mediante encuesta de Moodle

3. La evaluación por parte del profesorado se ha realizado en una sesión conjunta del equipo docente que imparte las diferentes asignaturas de este módulo 1 y la dirección del centro. En general, podemos señalar que se ha valorado muy positivamente el Trabajo de grupo planteado en cada una de las asignaturas, aunque se considera positivo de cara 
al futuro la limitación de las prácticas individuales y grupales por asignatura, debido a la carga de trabajo que han tenido los alumnos y alumnas en este primer módulo.

A continuación, describimos los resultados académicos obtenidos en la convocatoria de enero (curso 2011-2012), así como un breve análisis de los mismos (ver Tabla 7).

Tabla 7: Resultados académicos de la asignatura en el Grado de Educación Infantil y de Educación Primaria

\begin{tabular}{|l|l|l|}
\hline Calificación & $\%$ & $N^{o}$ de alumnos/as \\
\hline Matricula de Honor & $2,48 \%$ & 3 \\
\hline Sobresaliente & $7,44 \%$ & 59 \\
\hline Notable & $57,85 \%$ & 171 \\
\hline Aprobado & $17,36 \%$ & 25 \\
\hline Suspenso & $7,44 \%$ & 22 \\
\hline No presentado & $7,44 \%$ & 11 \\
\hline Total & $100 \%$ & $\begin{array}{l}291 \\
121 \text { (Ed. Infantil) } \\
170 \text { (Ed. Primaria) }\end{array}$ \\
\hline
\end{tabular}

口

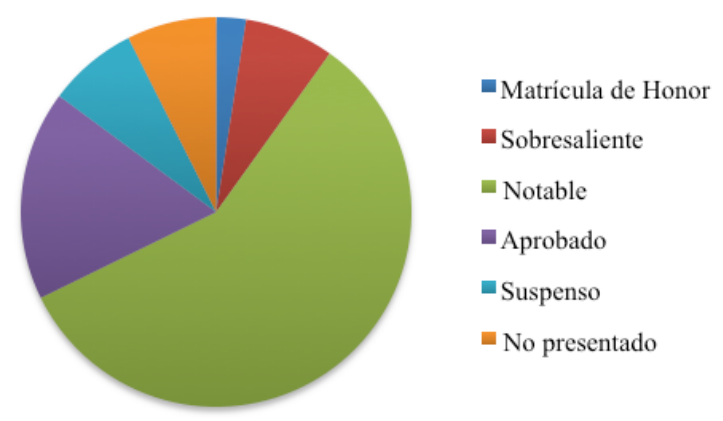

$\mathrm{Si}$ analizamos los datos aportados en la tabla anterior, podemos concluir que más del $90 \%$ del alumnado (que ha seguido el proceso y se ha evaluado) ha superado la asignatura, obteniendo una calificación de matrícula de honor el 1,03\%, el 20,27\% de sobresaliente, el 58,76\% de notable y el 8,59 de aprobado. Hay que considerar que el alumnado que ha suspendido la asignatura, no debe desarrollar de nuevo todas las prácticas sino aquellas en las que no ha alcanzado las competencias específicas. Por último y en relación al porcentaje de alumnado no presentado es un 7,56\%, debido a la modalidad presencial del grado que dificulta a los alumnos y alumnas que están trabajando poder simultanearlo con los estudios de grado.

Los instrumentos de evaluación de las prácticas individuales y del trabajo grupal han sido los siguientes: prácticas individuales (que ha supuesto un $10 \%$ de la calificación final) y el trabajo grupal y su presentación oral (que ha supuesto un $30 \%$ de la calificación final).

\section{Resultados y/o conclusiones}

Al ser una experiencia tan reciente, estamos todavía realizando la evaluación del proceso seguido. Con el alumnado se ha llevado a cabo un proceso evaluativo complementario, cuyo resultado ha sido muy positivo (encuesta mediante Moodle y sesión de evaluación conjunta). El profesorado está muy satisfecho con el trabajo realizado, aunque lógicamente queda pendiente la realización de una evaluación final de cara a mejorar en el próximo curso académico. 
Al respecto, podemos decir, que, en general, creemos que a través de esta actividad hemos conseguido desarrollar y llevar a cabo tanto en las prácticas individuales como en el trabajo grupal toda una serie de dinámicas comunicativas muy enriquecedoras. En este contexto, podemos afirmar que desde un primer momento nuestro alumnado ha estado en contacto directo en el centro educativo elegido, y posteriormente ha tenido oportunidad de conocer la realidad diversa y plural, analizada por los demás grupos en otros centros escolares de nuestra comunidad. Además, una vez realizada la exposición oral han podido tomar parte en los debates establecidos en clase para aclarar diferentes concepciones sobre la educación, el bilingüismo, modos idóneos de comunicación oral/escrito entre los diferentes estamentos, etc.

Nos gustaría, por lo tanto, presentar esta experiencia en esta revista, por una parte para poder reflexionar conjuntamente sobre la idoneidad de este tipo de prácticas con el objetivo de potenciar tanto el aprendizaje autónomo como grupal en materias como la tratada, en la que la práctica es fundamental para comprender la teoría; $y$, por otra parte, para ofertar propuestas formativas coherentes teniendo siempre en cuenta la particularidad de este tipo de alumnado bilingüe.

Finalmente, no podemos olvidar la realidad sociolingüística que presenta Euskadi, con dos idiomas oficiales tan alejados entre sí y diferentes planteamientos educativos a la hora de abordar la enseñanza-aprendizaje de la lengua vasca. En este contexto, planteamos diferentes cuestiones para la reflexión: ¿Cómo abordar la cuestión de la competencia comunicativa entre nuestros alumnos y alumnas en otras variedades dialectales (vizcaíno, guipuzcoano, navarro, labortano, etc.) que no sean la estándar?, ¿Cómo influyen los nuevos proyectos/modelos educativos trilingües o experiencias CLIL sobre la competencia comunicativa en lengua vasca? ¿Es posible superar el actual sistema de modelos lingüísticos para mejorar la competencia en comunicación lingüística en lengua vasca, atendiendo a los bajos resultados en las sucesivas evaluaciones diagnósticas realizadas entre nuestro alumnado?

\section{Agradecimientos}

Esta investigación se ha llevado a cabo gracias a la subvención del proyecto MICINN- FFI201128324. 


\section{REFERENCIAS}

Barquín, A. y Ruiz Bikandi, U., (2007). "Hizkuntzen kudeaketa eskolan”. En X. Aierdi eta B. Uranga (ed.), Euskara, inmigrazioa eta hizkuntza eskubideak (pp. 43-48). Bilbo: Ikuspegi eta Unesco Etxea.

Basterra, A. (2009). "El Tratamiento Integrado de Lenguas en Euskadi": http://www.slideshare. net/AnaBasterra/tratamiento-integrado-de-lenguas-en-euskadi [Consultado: 15-01-2012]

Bialysto, K. E. (2007). "Acquisition of literacy in bilingual children: A Framework for research". Language Learnings 7, 45-77.

Cambra, M., et al. (2008). "Los procesos de reflexión de los docentes y la innovación en las aulas plurilingües”. En A. Camps y M. Milian (coord.), Miradas y voces. Investigación sobre la educación lingüistica y literaria en entornos plurilingües (pp. 45-60). Barcelona: Graó.

Canale, M. (1989). From Communicative Competence to Communicatice Language Pedagogy. En Richards y R. Schmidt (eds). Language and Communication. London, Longman, 1983. En Hornberger, N. Trámites and transportes. The Acquisition of Second Language Communicative Competence for One Speech Event in Puno. Perú: Oxford University Press. En Applied Linguistics 10(2).

Casalmiglia, H. y E. Tusón (1999). Las cosas del decir. Manual de análisis del discurso. Barcelona: Ariel.

Cassany, D., M. Luna y G. Sanz (1994). Enseñar lengua. Barcelona: Grao.

Castelló, M. (coord.) (2007), Escribir y comunicarse en contextos científicos y académicos: conocimientos y estrategias. Barcelona: Graó.

Castillo, S. y Cabrerizo J., (2010). Evaluación educativa de aprendizajes y competencias. Madrid: UNED-Pearson.

Chomsky, N. (1965). Aspects of the Theory of Syntaxt. Cambridge, Mass, MIT Press.

Consejo Escolar de Euskadi (2005). Informe sobre la situación de la enseñanza en la CAV. Vitoria-Gasteiz.

Cots J.M., Ibarraran, A., Irún M., Lasagabaster, D., Llurda, E. y Sierra, J.M. (2010). Plurilingüismo e interculturalidad en la escuela. Reflexiones y propuestas didácticas. Barcelona: Horsori.

Cummins, J. (2005). "La hipótesis de la interdependencia 25 años después: la investigación actual y sus implicaciones para la educación bilingüe”. En D. Lasagabaster y J. M. Sierra (eds.) Multilingüismo y multiculturalismo en la escuela. Barcelona: ICE de la Universitat de Barcelona/Horsori, 113-132.

Etxeberria, F. y U. Ruiz Bikandi, (2002). ¿Trilingües a los 4 años?. Donostia: Ibaeta Pedagogía.

EUSTAT: Estadísticas sobre enseñanza (2012). Gasteiz: www.eustat.net [Consultado: 15-01-2012]

Garay, U. y A. Etxebarria (2010). "Irakasleen komunikazio-gaitasuna hausnarketarako gaia", Uztaro $73,39-48$.

Hirst, L.A. y Slavik, C. (1990). Cooperative Approaches to Language Learning. En Jon Reyhner (ed.), Effective Language Education Practices and Native Language Survival: Proceedings of the Ninth Annual Native American Language Issues Institute (pp. 133-42). Choctaw, OK: Native American Language Issues.

Iriondo, N. (2009). Idatziz idatzi. Donostia: Erein.

Ikuspegi (2008). Las lenguas de los inmigrantes en el País Vasco. Vitoria-Gasteiz: Observatorio Vasco de la Inmigración.

Lasagabaster, D. y J.M. Sierra, eds. (2005). Multilingüismo, competencia lingüística y nuevas tecnologías. Barcelona: ICE-Horsori.

Montolio, E. (coord.) (2009), Manual práctico de escritura académica, Barcelona: Ariel.

Noguerol, A. (2008). "El tratamiento integrado de las lenguas en el marco europeo". Textos, 47.

Ruiz Bikandi, U. y A. Tusón Valls (2008). "El Tratamiento Integrado de Lenguas". Textos 47.

Sainz, M. (2003). "Hezkuntza: eleaniztasuna eta kulturaniztasuna. Irakaslearen eginkizuna eta gaitasunak". http://www.mugak.eu/gunea/arauak/edu/iri/hez [Consultado: 15-01-2012]

Sánchez Miguel, E. (1999). Los textos expositivos: estrategias para mejorar su comprensión, Madrid, Santillana. 
Solé, I. (2006). Estrategias de lectura, Barcelona: Grao.

Vázquez, G. (coord.) (2001), El discurso académico oral, Madrid: Edinumen.

Vilá I Santasusana, M. (coord.) (2005). El discurso oral formal: contenidos de aprendizaje y secuencias didácticas, Barcelona: Grao.

Vila, I., Siqués, C. y Roig, T. (2006). Llengua, escola i inmigració: un debat obert. Barcelona: Graó.

Zabaltza, X. (2007). "Inmigrazioa eta eskubide linguistikoak". En X. Aierdi y B. Uranga (ed.) Euskara, inmigrazioa eta hizkuntza eskubideak (pp. 59-62). Bilbo: Ikuspegi eta Unesco Etxea.

\section{SOBRE LOS AUTORES}

Asier Romero Andonegi: Doctor en Filología Hispánica y Profesor Titular de la Universidad del País Vasco. Ha desarrollado su labor investigadora en el campo de la lingüística y de la enseñanza de lenguas. Pertenece al grupo de investigación consolidado EUDIA de la Universidad del País Vasco, y miembro del grupo de investigación AHODIKER de la Universidad del País Vasco. Ha publicado más de 40 artículos de investigación, capítulos de libros y libros, centrados en la lingüística y en la didáctica de las lenguas.

Iñaki Gaminde: Doctor en Filología Vasca y Profesor Titular de la Universidad del País Vasco. Es el responsable del grupo de investigación AHODIKER, y miembro del grupo de investigación EUDIA de la Universidad del País Vasco y autor de más de centenar de publicaciones vinculadas con la lingüística y más concretamente relacionados con la Prosodia.

Aintzane Etxebarria: Doctora en Filología Vasca por la Universidad de Deusto, actualmente imparte docencia en la Universidad del País Vasco (UPV/EHU), en el Departamento de Didáctica de la Lengua y la Literatura de la Escuela Universitaria de Magisterio de Bilbao.

Urtza Garay: Doctora en Psicodidáctica por la UPV-EHU, universidad donde actualmente es profesora del Departamento de Didáctica de la Lengua y la Literatura. Sus líneas de investigación son las nuevas tecnologías aplicadas a la educación y el proceso de enseñanza-aprendizaje de las lenguas en la escuela. 